\title{
DIOS COMO VERDAD SUBJETIVA Y PARADOJA EN EL PENSAMIENTO RELIGIOSO DE SOREN KIERKEGAARD
}

\section{God as subjective truth and paradox in religious thought of Soren Kierkegaard}

Fernando Bravo Peña

Universidad del Valle

\begin{abstract}
Resumen
El texto analiza la concepción de Dios considerando dos elementos: Dios como verdad subjetiva y paradoja. Básicamente, Dios como verdad subjetiva significa que la creencia religiosa es un fenómeno personal e interior. La paradoja del Dios cristiano se encarna en la figura de Cristo: ¿cómo puede Dios manifestarse como un ser humano? Por lo tanto, en el cristianismo hay dos caminos: creer en Dios o no creer en Dios. Esta disyuntiva tiene un fundamento en una premisa de Kierkegaard: la creencia en Dios no puede ser racionalizada ni demostrada.
\end{abstract}

Palabras clave: Dios, verdad subjetiva, paradoja, cristianismo.

\begin{abstract}
The text analyzes the God's conception considering two elements: God as subjective truth and paradox. Basically, God as subjective truth means that the religious belief is a personal and interior phenomenon. The paradox of the Christian God is personified in Christ's figure: how can God demonstrate as a human being? Therefore, in the Christianity there are two ways: to believe in God or not to believe in God. This dilemma has a foundation in Kierkegaard's premise: the belief in God cannot be rationalized not demonstrated.
\end{abstract}

Keywords: God, subjective truth, paradox, Christianity. 


\section{Introducción}

Para Kierkegaard, el cristianismo se ha convertido en una fábula, le resulta vergonzoso e insultante que cualquiera pueda identificarse como creyente. ¿Es tan sencillo ser cristiano? ¿Creer en Dios en la figura de Cristo como Dios-hombre es tan fácil? Kierkegaard considera que los creyentes coetáneos de su época -la Dinamarca luterana del siglo XIX- se ven a sí mismos como verdaderos cristianos; sin embargo, esta auto-representación tiene su causa en la vivencia de un cristianismo que no es genuino, sino artificioso. De este modo, Kierkegaard afirma que el verdadero cristianismo ha sido suplantado por una versión falsa de este mismo. Esta versión distorsionada fue denominada por el filósofo danés como la cristiandad, en ella se congregan aquellos creyentes que de forma natural y espontánea asumen su rol como tal. De esta manera, Kierkegaard atestigua -con cierto fatalismo e ironía- que el calificativo de cristiano se ha convertido en un rótulo más, que no difiere, en modo alguno, del que puede poseerse por tener una determinada nacionalidad o tendencia política. El cristianismo se ha deformado porque los supuestos creyentes han abrazado la fe desde la tradición o la cultura. Es decir, las personas se identifican como cristianas porque hacen parte de un entorno cristiano, así como quien dice ser danés por nacer en Dinamarca. Para Kierkegaard, el ser cristiano no se basa en la pertenencia a una tradición o cultura religiosa. El cristianismo debe provenir del interior, de una convicción profunda y personal en la divinidad, es decir, lo que reclama Kierkegaard es sinceridad y pasión por la creencia religiosa. Pero, esta pasión y sinceridad debe tener un fundamento, a saber: la creencia en Cristo -que es el personaje fundacional del cristianismo- no es algo natural, espontáneo o evidente. Cristo como dualidad Dios-hombre encarna -desde la perspectiva de Kierkegaarduna contradicción que embiste contra toda lógica o evidencia. En otras palabras, la figura de Cristo fractura la razón, quien decida creer en él debe abandonar la razón y entregarse por completo a la fe.

\section{Dios como verdad, un diálogo de Kierkegaard con la filosofía socrática}

Para Kierkegaard, existen dos clases de verdad: la verdad objetiva y la verdad subjetiva. ¿En qué consiste cada una? La verdad objetiva es relativa a las ciencias que se rigen por principios o métodos racionales que posibilitan un conocimiento objetivo de su objeto de estudio. No obstante, aquello que es verdaderamente valioso para el ser humano -en términos existenciales-, solo puede ser asumido como una verdad subjetiva. ¿Soy un verdadero 
cristiano? ¿Cómo puedo ser salvo? Estas son preguntas cuya respuesta se encuentra en el terreno de la subjetividad, porque tales interrogantes únicamente tienen sentido y significado para el sujeto que los está formulando desde su propia existencia. Por ende, podemos concluir, con Strathern (1999, 53-4), lo siguiente:

Hay dos especies de verdad para Kierkegaard. La verdad objetiva, como las de la historia o la ciencia, que se refieren al mundo exterior y pueden ser verificadas por referencia a criterios externos. ... A diferencia con la verdad objetiva, la verdad subjetiva no tiene criterios objetivos. Kierkegaard da el ejemplo de dos hombres en una plegaria. El uno reza al "concepto verdadero de Dios" (el cristiano para Kierkegaard) pero lo hace con un "espíritu falso". El segundo es un pagano y reza a un ídolo primitivo, pero con una "pasión entera por el infinito". Para Kierkegaard el segundo hombre es el que tiene mayor verdad subjetiva, porque reza "en verdad". La noción de verdad subjetiva en Kierkegaard es similar a la de sinceridad sólo que más intensa. Involucra un compromiso interior apasionado.

La verdad religiosa -nos dice Kierkegaard- es pasión, porque se trata de la verdad personal e individual, la verdad se siente, se vive, pero no se razona. Dios es la verdad, por ende, solo se accede a él por fe, no por la razón, porque Dios no puede ser conocido, comprendido o demostrado. Kierkegaard plantea un contraste alrededor de lo que significa la verdad en dos personajes, que a su parecer tienen tanto divergencias como puntos en común, se trata de Sócrates - protagonista de la filosofía griega- y Cristo -figura fundacional del cristianismo-.

Para Sócrates, la verdad se encuentra en cada individuo, por ende, la persona debe mirar sobre sí para encontrarla, el método socrático conocido como mayéutica, intenta develar aquella verdad contenida en la interioridad. Kierkegaard $(1999,27)$ condensa la posición socrática respecto a la verdad de la siguiente manera:

A un hombre le resulta imposible buscar lo que sabe y le es igualmente imposible buscar lo que no sabe, porque lo que sabe no puede buscarlo, pues ya lo sabe, y lo que no sabe tampoco puede buscarlo, pues ni siquiera sabe qué debe buscar. Sócrates resuelve la dificultad a través de la idea de que todo aprender y todo buscar es sólo recordar, de tal modo, que el ignorante no necesita más que rememorar para llegar a ser consciente de lo que sabe. Así pues, la verdad no le es inculcada, pues estaba en él.

En el socratismo, la búsqueda de la verdad parte de la premisa: el hombre es ignorante de la verdad, de lo contrario, la verdad no tendría que ser buscada o rememorada. La ignorancia no puede ser referida como vacío o ausencia de la 
verdad, sino como olvido u ocultación. La verdad se oculta en la ignorancia, el papel del maestro -Sócrates- es conducir a la persona para que recordar una verdad que ya estaba contenida en ella. No es una verdad ajena a su interioridad, esta se puede acceder por reminiscencia o recuerdo. En el socratismo, la posición del maestro frente al discípulo -que apela a la reminiscencia para encontrar la verdad- es netamente periférica, el maestro cataliza o ayuda a parir una verdad que estaba de antemano en el discípulo mismo. Para Sócrates, la verdad tiene, entonces, dos componentes para que pueda ser accedida: mayéutica y reminiscencia. La relación entre estos dos elementos se puede presentar del siguiente modo:

Por una parte, en efecto, Sócrates, ese partero espiritual, traía al mundo a las inteligencias: al igual que su madre Fenareta, comadrona de oficio, asistía a los partos de los cuerpos, así también él ayudaba a nacer a los espíritus a la verdad de ellos mismos. La mayéutica designa el arte de partear los espíritus, arte mediante el cual Sócrates conducía a sus interlocutores a descubrirse a sí mismos, a tomar conciencia de sus propias riquezas implícitas. (...) Tal es la doctrina de la reminiscencia: durante nuestras experiencias anteriores hemos contemplado las Ideas, las cuales, desde entonces, permaneces en nosotros como recuerdos. Aprender no es, así, sino recordar o rememorar la verdad percibida antiguamente. Todo ejercicio filosófico está dirigido a dominar y organizar este contenido secreto, oculto, fruto de una lejana contemplación. (Russ 1999, 490)

Kierkegaard se pregunta si Cristo puede ser concebido como un maestro -al modo socrático-, en donde el papel del maestro es periférico y accidental en el encuentro con la verdad, pues la verdad se encuentra en el discípulo. La respuesta de Kierkegaard es negativa, Cristo no puede ser concebido como un maestro socrático porque "... quien da al discípulo no meramente la verdad, sino incluso la condición, no es un maestro" Kierkegaard (1999, 31). Si en el cristianismo, la verdad es dada a la persona de manera externa, porque la verdad -su condición de verdad- es Dios mismo, entonces, estar en "La no verdad no es sólo estar fuera de la verdad, sino estar en polémica con la verdad, lo que se expresa afirmando que él mismo ha perdido y pierde la ocasión" (Kierkegaard, 1999, 32). Es decir, la no-verdad se manifiesta en la resistencia del ser humano para acoger la verdad-Dios-, y quien se encuentra en el estado de la no-verdad, lo está por causa propia, por ende, Kierkegaard $(1999,32)$ se pregunta: “Cómo podríamos llamar a ese estado de ser la no-verdad y serlo por culpa propia? Llamémosle pecado". Si el hombre es la no-verdad, y la no-verdad es pecado, entonces, la verdad debe provenir del exterior, en este caso de Dios, por lo cual Dios es la verdad y la condición 
de la verdad. Cristo no es un maestro socrático, sino un salvador, en palabras de Kierkegaard (1999, 33):

¿Cómo denominare a un maestro que le da de nuevo la condición y, con ella, la verdad? Llamémosle: salvador, porque salva al discípulo de la no libertad, lo salva de sí mismo; libertador, porque libera a quien se había aprisionado a sí mismo, y nadie está tan terriblemente cautivo y ningún cautiverio resulta tan imposible de quebrar, como aquel en el que el hombre se retiene a sí mismo. (...) Pero si el maestro le concedió la condición y la verdad, será también redentor, porque aleja la ira que pesaba sobre la falta.

Cuando el discípulo pasa de la no-verdad -el pecado- a la verdad -Dios-, irrumpe un nuevo ser, "llamemos a este cambio conversión" (Kierkegaard 1999, 34). No obstante, Kierkegaard reclama que si bien Dios es la verdad y la condición de la verdad, esta conversión a la verdad solo puede suceder si la persona elige aceptar esa verdad. Es decir, se necesita de la fe para que de ella misma pueda germinar una conversión. Cuando el ser humano elige por la fe a Dios, se hace consciente de su estado de no-verdad o estado de pecado, lo cual le produce una pena, por ser ahora consciente de su estado de no-verdad, "Llamemos a esa pena arrepentimiento, porque ¿qué es el arrepentimiento sino mirar atrás acelerando la marcha hacia aquello que está adelante" (Kierkegaard 1999, 34). El paso de la no-verdad a la verdad, Kierkegaard lo traduce como un paso del no-ser al ser invocando la imagen de un nacimiento:

Mientras en la no-verdad, una vez recibida la condición y la verdad, se operó en él un cambio como del no-ser al ser. Este paso del no-ser al ser es como el de un nacimiento. Quien existe no puede nacer y, sin embargo, éste nace. Vamos a denominar a ese paso renacimiento... (Kierkegaard 1999, 34)

El renacimiento que implica el paso de la no-verdad a la verdad, se da en un instante, es decir, el punto de quiebre que permite el tránsito de la no-verdad a la verdad, se produce en la temporalidad humana, y es un instante, pero "decisivo por estar lleno de eternidad. Para este instante tendremos que contar con un nombre singular. Llamémosle: plenitud en el tiempo (Kierkegaard 1999, 34).

Kierkegaard enfatiza que dentro del cristianismo, el discípulo queda en deuda con el maestro, ya que, el discípulo por sí mismo no puede encontrar la verdad. La finalidad de Dios -como verdad y condición de esta misma- es posibilitar la plenitud en el tiempo; mientras que el socratismo se concentra en la reminiscencia de la verdad. La plenitud en el tiempo se refiere a aquel momento en el que el individuo decide adentrarse en el camino de 
la fe. En el socratismo, la verdad y su acceso por reminiscencia plantea un acercamiento racional a la verdad, por ende, su comprensión es igualmente racional. De manera contraria, en el cristianismo, la verdad no es accedida por la razón, sino por la fe. Para Kierkegaard, existen dos posibilidades frente a la verdad: la verdad puede estar en el ser humano, en tal caso -que es la posición socrática-, el rol del maestro es contingente o periférico; en la otra posibilidad -que es la posición cristiana-, la verdad está fuera del ser, y en esa medida, el salvador -Cristo- es la verdad y la condición que necesita el ser humano para que pueda acceder a ella. El encuentro con la verdad Dios- no es doctrinal, sino existencial, es un encuentro dialógico entre la persona y Dios.

\section{La verdad de la fe en el luteranismo}

Para Martín Lutero, la verdad religiosa es esencialmente subjetiva, la fe no puede exteriorizarse, ya que esta se manifiesta como un fenómeno de interioridad: "Dios habita en el interior y es preciso que la salvación se experimente no como lo exterior-dogma, ritos, sacramentos- sino como lo más interior y esencial de uno mismo por gracia" (Ropero 1999, 318).

En el luteranismo, la salvación es dada al ser humano por gracia divina, y este debe tener la convicción de que efectivamente es salvo, no por mérito propio sino por la voluntad de Dios. El convencimiento de la salvación parte de la interioridad, de la fe de cada persona en relación con su situación ante Dios. En la concepción luterana, la creencia religiosa es una verdad interior, por ejemplo, los sacramentos por sí mismos no son expresiones de la fe. Los sacramentos no tienen valor por sí mismos, la operatividad o eficacia no es intrínseca al sacramento mismo, sino por la gracia de Dios y a la fe subjetiva del creyente que cree en ella -la gracia divina-. Los sacramentos que acepta el luteranismo son básicamente dos: el bautismo y la eucaristía. Los sacramentos tienen una dualidad: se manifiestan de manera externa e interna. ¿Qué significa esto? Los sacramentos tienen una manifestación física o visible - exterior- y otra espiritual o invisible -interior-. Por ejemplo, en el sacramento del bautismo, el agua es la manifestación física o exterior; pero la manifestación espiritual es interna, propia del creyente que por fe cree en la gracia divina que lo hace merecedor de la justicia divina que no le imputa los pecados, sino que los encubre y lo hace digno de la salvación. En el sacramento de la eucaristía, el pan y el vino son la manifestación exterior o visible, y la interior o espiritual es que por fe se cree en la transustanciación de ese pan y vino en el cuerpo y sangre de Cristo. En palabras de Martín Lutero (1519): 
Además hay gente que le gusta simpatizar emocionalmente con Cristo (...) Esta clase de gente incluye a los fanáticos que tratan de enseñar a la gente que reciben una gran bendición sólo asistiendo a la celebración de la Santa Cena, parándose allí y viendo que se celebre. Tratan de convencer a la gente que sólo presentarse y ver una misa automáticamente obra la bendición por el acto mismo de hacerlo. Quisieran llevar a la gente a creer que la Cena del Señor no tiene nada que ver con la fe en la promesa de la Santa Cena, ni de ser digno para recibir la Santa Cena. La Cena no fue instituida para su propio beneficio, como si el propósito fuera sólo celebrarla. Se dio con el fin de meditar en la pasión de Cristo. Si no lo hacemos, convertimos la Santa Cena en una obra humana. Lo Hacemos algo inútil, no importa que tan buena sea en sí misma. ¿De qué sirve que te sirve que Dios sea Dios, sino lo es para ti? ¿Qué utilidad tiene comer y beber sino te beneficia a ti? Debemos tener miedo de pensar que nos haremos mejores sólo porque celebramos mucho la Santa Cena, mientras que al mismo tiempo no recibimos su verdadero beneficio.

Para el luteranismo, la concepción de Dios está basada en la formula Cristo para el ser humano, en la cual se trata de rescatar a Dios no como ente abstracto e impersonal, sino como una experiencia personal. Para Martin Lutero, la creencia es una vivencia, y esa vivencia debe confrontarnos individualmente, por ende, es necesario "... creer profundamente, y nunca dudar, que en verdad eres tú el que mató a Cristo" (Lutero 1519). Entonces, la salvación como acto de reconciliación entre el ser humano y Dios, mediado o dispuesto por la gracia, que no anula en modo alguno que "la reconciliación es un acto supremamente interno, particular y personal" (Balderas Vega 2013, 48), para quienes desean creer como verdad subjetiva que son salvos por la voluntad divina. La fe no es para Martín Lutero un corpus teológico o una práctica ritual, sino una experiencia individual, personal o de conciencia entre la persona y Dios. El corpus teológico o la práctica ritual son los signos visibles o exteriores de la $\mathrm{fe}$, pero que no la acotan ni la definen totalmente. La dimensión más importante de la fe -para el luteranismo- es la interior, porque apela a la conciencia de cada individuo en relación a su situación ante Dios. La verdadera espiritualidad debe ser vivida interiormente, esta solo tiene sentido a nivel personal, porque solo en el nivel interior -de nuestra conciencia- podemos asimilar a Dios como una experiencia de vida. Martín Lutero (1519) afirma lo siguiente:

Permite que diga esto de forma clara y abierta, para que todos oigan. Todo el que medita en los sufrimientos de Cristo en la forma correcta por un día, por una hora, aun por quince minutos, está haciendo algo mucho 
mejor que ayunar todo un año, rezar los salmos todos los días, o escuchar cien misas. La meditación correcta en el sufrimiento cambia el carácter de la persona.

Kierkegaard como creyente educado en la iglesia luterana danesa plantea que la verdad debe ser interiorizada, porque solo adquiere valor, significado o sentido, cuando es percibida de esa forma, como verdad interior. ¿Por qué debe ser interiorizada la verdad -Dios-?:

Søren Kierkegaard sostiene que la verdad no puede separarse del sujeto que la afirma; esto lo sustenta respecto a la verdad religiosa que le preocupa sustancialmente, ya que es la nos pone en juego a nosotros mismos en el punto más elevado. No hay otra verdad para Kierkegaard que la que se refiere al sujeto existente y su interioridad. (Balderas Vega 2013, 48)

Lo realmente importante de la verdad, especialmente, la religiosa, es cómo se afirma esa verdad, por lo tanto, debemos atender la comparación que realiza Kierkegaard entre dos personas que dirigen una invocación a la divinidad. Una dirige su plegaria a la divinidad cristiana, pero lo hace de una manera poco sincera, sin pasión interior; otra dirige su plegaria a una divinidad pagana -se puede suponer que Kierkegaard se refiere al caso de los seguidores de una religión diferente a la cristiana-, pero, lo hace con pasión y sinceridad interior. ¿En cuál de los hay más verdad? El filósofo danés asentirá que, en el pagano hay más verdad, porque se acercó de forma más íntima a la divinidad, a diferencia, del sujeto cristiano que lo hizo sin asumir una disposición genuina de acercamiento a Dios. Ello da como resultado la siguiente situación: para Kierkegaard, "el criterio de verdad es la pasión; es la intensidad de la pasión de mi sentimiento, la que forma la realidad del término a la que me ligo" (Balderas Vega 2013, 48).

\section{Cristo como paradoja, el quiebre de la razón}

Kierkegaard reclama que el cristianismo ha dejado de vivir o sentir a Dios como una verdad subjetiva, si Dios no puede vivirse como una verdad subjetiva, entonces no hay fe. Por ende, aquellos que se denominan como cristianos no lo son realmente, porque les falta sinceridad o pasión en su relación con Dios. Este reclamo hace plantear a Kierkegaard dos formas de vivir la esfera religiosa que son irreconciliables, a saber: la cristiandad y el cristianismo. Por el momento, podemos adelantar una distinción básica y general entre las dos:

La Cristiandad consiste fundamentalmente en pertenecer a una comunidad eclesial _la Iglesia Luterana de Dinamarca- representante del "orden establecido". Es una pertenencia que no implica 
un modo determinado de vida: uno es cristiano porque ha sido bautizado cuando era niño, porque va a la iglesia el domingo, escucha el sermón del pastor y canta himnos. Pero aquello que el cristiano escucha el domingo no influye en su vida del lunes siguiente. La Cristiandad, dirá Kierkegaard, es una ilusión. La tarea que se propone el filósofo danés - tarea que interpreta como un encargo divino- será develar esa ilusión y ese engaño de la Cristiandad, y presentar el verdadero cristianismo, que no es una doctrina para ser expuesta sino para ser vivida. (Fazio 2007)

Kierkegaard pretende poner en escena las diferencias presentes entre el cristianismo y la cristiandad, especialmente, en la concepción de Cristo como paradoja, la cual ha sido abandona por la cristiandad, que presenta un Cristo al que fácilmente todos pueden acceder y creer, de ahí que sea tan cómodo proclamarse cristiano. Por el contario, el cristianismo debe testificar la paradoja que es Cristo. ¿Por qué Cristo es una paradoja? Kierkegaard (2009, 51) lo expone así:

Que un hombre particular sea Dios, que se presente como Dios, es ciertamente el escándalo, pero ¿qué es el escándalo, qué es lo escandaloso? Lo que va contra toda (humana) razón. Pero demostrar significa convertir algo en lo racional-real dado. ¿Puede lo que contradice toda razón convertirse en lo racional-real?
Cristo es una paradoja, porque se manifiesta como un hombre particular cualquiera, esto, para Kierkegaard, es lo escandaloso para la razón, la dualidad presente en Cristo, como Dios y hombre, que solo puede ser objeto de fe, no de razonamiento. De esta premisa, se concluye que el escándalo es condición necesaria para tener fe, no se puede llegar a la fe sin haberse escandalizado previamente; no obstante, el escándalo debe superarse a través de la fe, si se desea alcanzarla. ¿Cuál es la relación entre fe y escándalo?

El escándalo es una categoría propiamente cristiana, que guarda relación con la fe. La posibilidad del escándalo es la encrucijada, o como estar plantado en la encrucijada. De la posibilidad del escándalo se parte o hacia el escandalo o hacia la fe; pero jamás se llega a la fe sin pasar por la posibilidad del escándalo. (Kierkegaard 2009, 99)

El escándalo frente a la dualidad de Cristo como Dios-hombre se manifiesta de dos formas: primera, el escándalo respecto a un hombre particular que habla y actúa en la determinación de ser Dios; segunda, el escándalo respecto al hombre que pretende manifestarse como Dios sea un hombre común. La primera forma de escándalo es denominada por Kierkegaard como la posibilidad esencial del escándalo en la dirección de la majestad, y la segunda, como la posibilidad esencial del escándalo en la dirección de la pequeñez. 
Kierkegaard, para indagar sobre la forma de escándalo, se remite a un pasaje de la $\mathrm{Biblia}^{2}$, que reza:

Cuando Jesús terminó de dar instrucciones a sus doce discípulos, se fue de allí a enseñar y a predicar en las ciudades de ellos. Y al oír Juan, en la cárcel, los hechos de Cristo, le envió dos de sus discípulos, para preguntarle: ¿Eres tú aquel que había de venir, o esperaremos a otro? 4 Respondiendo Jesús, les dijo: Id, y haced saber a Juan las cosas que oís y veis. Los ciegos ven, los cojos andan, los leprosos son limpiados, los sordos oyen, los muertos son resucitados, y a los pobres es anunciado el evangelio; y bienaventurado es el que no halle tropiezo en mí. (Mt 11.1-6)

Kierkegaard examina este pasaje bíblico en concreto y hace algunos apuntes sobre la figura de Cristo como Dios-hombre. En primera instancia, Cristo nunca se autoproclama de forma directa como Dios, parece sugerirlo, lo insinúa, pero nunca lo dice explícitamente. Esto constata una característica del cristianismo, que lo diferencia de la cristiandad, a saber: la verdad del cristianismo no puede ser demostrada, esta es la esencia del cristianismo que ha sido traicionada por la cristiandad. En la cristiandad, los creyentes asumen su creencia en Cristo de una manera naturalizada, como si fuese totalmente evidente que Cristo es Dios-hombre. ¿Entonces, los milagros no prueban que ese hombre particular es Dios? Kierkegaard respondió a este interrogante de manera negativa, aludiendo que el milagro no puede ser el fundamento de la fe. De manera inversa, los creyentes que hacen parte de la cristiandad consideran, con total naturalidad y evidencia irrefutable, que el milagro es prueba de que un hombre particular sea Dios. Si el milagro fuera propiamente una prueba para aceptar la fe, Kierkegaard comenta que no tendría sentido la afirmación de Cristo, cuando dice "bienaventurado aquel que no se escandalizare de mî" (Lc 7.23). Kierkegaard dice lo siguiente:

Si ha de tener sentido la afirmación de que el milagro demuestra quien es Cristo, entonces tendremos que empezar con que no sabemos quién es Êl, es decir, en situación de contemporaneidad con un hombre individual, que es como los demás hombres, en el cual no hay nada especial que ver directamente, un hombre individual, que hace el milagro y dice de sí mismo que hace el milagro. ¿Qué quiere decir esto? Quiere decir que este hombre individual se convierte en más que hombre, en algo cercano a Dios. ¿No es esto escandaloso? Tú ves algo inexplicable, milagroso (nada más que esto). Él mismo dice que es un milagro -y tú tienes delante de tus ojos un hombre individual-. El milagro no puede demostrar nada; pues si tu no crees que Él es quien dice ser, entonces niegas el milagro. El milagro puede despertar la atención -ahora estás en tensión, y 
todo depende de lo que tu elijas, el escandalo o la fe; es tu corazón el que ha de hacerse patente. (Kierkegaard 2009, 112)

¿Qué papel juegan los milagros en el luteranismo? Los milagros no pueden ser concebidos como fundamento o preámbulo de la fe, ya que esto opacaría el sentido de la fe, que es la convicción fuerte y profunda de la misión salvadora de Cristo, por la gracia divina, más allá de toda prueba, demostración o evidencia que intente dar razones para creer. De otro lado, el luteranismo cuestiona la relevancia del milagro -que finalmente se manifiesta en la alteración del orden natural, sensible, material- frente a la misión salvadora de Cristo, que es central y esencial, por su carácter eminentemente espiritual. ¿Por qué, entonces, hablan los evangelios de los milagros de Cristo? ¿Por qué los hizo? Para el luteranismo, Cristo hizo milagros fundamentalmente como muestra de compasión frente al dolor humano, pero la misión de Cristo es salvadora, y el acto que sella el destino de dicha misión no es, por ejemplo, la sanación de un enfermo o la multiplicación de los panes y peces, sino, la muerte en la cruz para la expiación de los pecados.

Respecto a la segunda forma de escándalo, Kierkegaard toma como punto de referencia el siguiente pasaje bíblico:
¿De dónde saca éste esta sabiduría y estos milagros? ¿No es éste el hijo del carpintero? ¿No se llama su madre María, y sus hermanos, Jacobo, José, Simón y Judas? ¿No están todas sus hermanas con nosotros? ¿De dónde, pues, saca éste todas estas cosas? Y se escandalizaban de él. (Mt 13. 55-57)

Aquí lo escandaloso surge de la determinación de Dios como un hombre corriente, perteneciente a una familia como lo puede ser cualquier ser humano. ¿Cómo puede Dios manifestarse como un hombre del común? ¿Cómo puede Dios soportar los sufrimientos de la muerte en la cruz como cualquier persona que se encuentra impotente ante su destino o situación? Esto es lo escandaloso para la razón. Kierkegaard explora otro pasaje bíblico en relación con esta forma de escándalo:

Entonces Jesús les dijo: - Todos os escandalizaréis de mí esta noche, pues escrito está: "Heriré al pastor y las ovejas serán dispersadas." Pero después que haya resucitado, iré delante de vosotros a Galilea. Entonces Pedro le dijo: - Aunque todos se escandalicen, yo no. Y le dijo Jesús: -De cierto te digo que tú hoy, en esta noche, antes que el gallo haya cantado dos veces, me negarás tres veces. Pero él con mayor insistencia decía: -Aunque tenga que morir contigo, no te negaré. También todos decían lo mismo. (Mc 14. 27-31) 
Pedro -dirá Kierkegaard- niega a Cristo, pero lo hace precisamente porque es una contradicción que Dios mismo se encuentre impotente ante su destino, incluso, es verosímil considerar que, la empresa que Cristo inició se encontró naufragando en el fracaso:

Cuando se le contempla clavado en la cruz como un malhechor, se puede afirmar muy bien que jamás hombre alguno, hablando humanamente, había conseguido menos, y que jamás causa alguna, hablando humanamente, estuvo tan perdida como la suya en este momento. (Kierkegaard 2009, 120)

La cristiandad abolió el escándalo, sin escandalo no puede existir fe, por eso es tan fácil denominarse como cristiano en la cristiandad, todo resulta plenamente despejado, que Dios mismo muera en la cruz como cualquier hombre o malhechor no es causa de escándalo; pero quien renuncia al escándalo, renuncia a la fe, y quien renuncia a la fe no puede ser cristiano verdaderamente. Sin el escándalo no se puede elegir la fe, es decir, el verdadero creyente debe encarar el escándalo y superarlo eligiendo creer, eligiendo la fe. Para Kierkegaard, llegar a ser un verdadero cristiano -hacer parte del cristianismo y no de la cristiandad- es realmente difícil, ya que la divinidad se muestra a la persona, aunque nunca de manera inmediata; de ser así, la fe no sería necesaria y tampoco haría irrupción el escándalo. El cristianismo debe vivirse como una paradoja, el escándalo siempre aparecerá conjuntamente con la fe. Para Kierkegaard, Cristo en su dimensión Dios-hombre es un signo contradictorio por su naturaleza dual, tanto humana como divina. La consecuencia de esta paradoja es que Cristo es incognoscible y, por ende, la comunicación directa con él no es posible. Kierkegaard (2009, 1445) dice lo siguiente:

Esto acontece con el Dios-hombre. Él es un signo, un signo de contradicción. Él está en la incognoscibilidad, por lo tanto toda comunicación directa es imposible. Para que la comunicación de un comunicante sea concretamente directa es necesario que no solamente la comunicación sea directa, sino que el mismo comunicante este directamente determinado. De no ser así, incluso la más directa de todas las expresiones de un tal comunicante, que tiene que ser inseparable de él, es decir, de aquello que él es, nunca será a pesar de toda comunicación directa. Cuando alguien dice directamente: yo soy Dios, mi Padre y yo somos la misma cosa, estamos ante una comunicación directa. Más si aquel que lo dice, el comunicante, es este hombre individual, un hombre individual completamente como los demás, entonces esa comunicación deja de ser totalmente directa. ... La comunicación contiene una contradicción al estar implicado en ella el que comunica, por lo que permanece como comunicación indirecta, que te enfrenta 
a una elección: si quieres creer a Él o no (...) Ciertamente Cristo ha dicho del todo directamente que Él es el unigénito del Padre, es decir, ha dicho del todo directamente el signo de contradicción. ¿Qué significa esto? Mira, aquí nos paramos de nuevo. Si Él es signo de contradicción no puede ofrecer una comunicación directa (...) Ciertamente Cristo ha dicho: cree en mí y esto es seguramente una expresión totalmente inmediata. Mas dándose el caso que el que lo dice es signo de contradicción, esta expresión inmediata en sus labios significa seguramente que creer no es algo totalmente directo, o dicho de otra manera, significa que su exigencia de que se crea es comunicación indirecta, que te enfrenta a una elección: si lo quieres creer a Él o no.

Kierkegaard afirma que la fe es una encrucijada, una paradoja, pues la fe es esencialmente elección, elegir entre escandalizarse o creer, esto es lo que ha olvidado la cristiandad. La cristiandad ha pretendido descifrar el cristianismo como si fuera un mensaje que puede ser comunicado y entendido en su totalidad. Incluso, se piensa que el cristianismo puede ser enseñado, de tal forma que quienes reciban la enseñanza religiosa se conviertan en cristianos automáticamente. El cristianismo es una vivencia, y en cuanto tal, requiere de la elección, es decir, elegir creer o escandalizarse. La fe no exige demostraciones ni pruebas, para Kierkegaard, la fe es el salto al absurdo, a la paradoja, a la contradicción. La fe se caracteriza como una pasión interior, en la cual el ser humano decide ponerse de frente a lo absoluto que es la divinidad. La cristiandad ha pretendido olvidar todo esto y ha personificado una imagen del cristianismo que a los ojos de Kierkegaard es vergonzosa, especialmente, por la caricaturización de la imagen de Cristo, presentándolo como un Dios que puede ser comprendido, descifrado y objetivado. La diferencia entre el cristianismo y la cristiandad es trasladada a la discrepancia entre el creyente imitador $y$ el creyente admirador. El imitador es aquel que se adentra en la contradicción de Cristo, es decir, en su majestad y pequeñez, vive la contradicción de Cristo como Dios-hombre. Por el contrario, el admirador no ve la contradicción de Cristo, únicamente su majestad, su aparente comunicación directa con el ser humano. De ahí que, el admirador no pueda vivir el cristianismo como devenir, paradoja, contradicción y sufrimiento. "El verdadero cristiano no es un simple admirador de Cristo, sino alguien que cree. Al dar el salto de la fe, que lo convierte en seguidor y contemporáneo de Cristo, acepta lo que Cristo es: Hombre-Dios" Balderas Vega $(2013,62)$.

De otro lado, Martín Lutero nos dice que Dios se manifiesta de forma oculta, indescifrable, incomprensible para la razón humana, a esta concepción de Dios, el luteranismo la 
denomina teología de la cruz. ¿Qué es la teología de la cruz? Martín Lutero (1518) comenta lo siguiente:

Las cosas inferiores y visibles de Dios son las opuestas a las invisibles, es decir, la humanidad, la enfermedad, la locura, lo «enfermo y estulto de Dios» (...) Puesto que los hombres han abusado del conocimiento de Dios a través de sus obras, ha querido Dios ser conocido por estos sufrimientos; con ello ha reprobado esa ciencia de lo invisible a base de lo visible, para que quienes no le han adorado tal como se manifiesta en sus obras lo hagan tal como se esconde en sus padecimientos (...) de tal manera que no basta ni aprovecha a nadie el conocimiento de Dios en su gloria y en su majestad, sino se le conoce también en la humildad y en la ignominia de la cruz. Así «confunde a la sabiduría de los sabios, etc.», como dice Isaías: «verdaderamente eres un Dios escondido». Por eso, cuando Felipe (Jn. 14), conforme a la teología de la gloria, dijo, «muéstranos al Padre», Cristo le llevó a la búsqueda de Dios por otro camino al contestarle: «Felipe, quien me ve a mí está viendo también al Padre». Por tanto, es en Cristo crucificado donde está la verdad teología y el conocimiento verdadero de Dios (...) El teólogo de la gloria llama al mal bien y al bien mal: el teólogo de la cruz llama a las cosas como son en realidad. Es evidente, porque al ignorar a Cristo, ignora al Dios que está escondido en sus sufrimientos. Prefiere así las obras a los sufrimientos, la gloria a la cruz, la sabiduría a la locura y en general, el bien al mal. Son aquellos a quienes el apóstol llama la cruz de Cristo, porque aborrecen la cruz y los sufrimientos y aman las obras y su gloria. De esta forma vienen a decir que el bien de la cruz es un mal y el mal de la obra es un bien, y ya hemos dicho que no se puede encontrar a Dios sino en el sufrimiento y en la cruz.

La teología de la cruz -del luteranismo- queda muy bien expresada en el siguiente pasaje bíblico:

La palabra de la cruz es locura a los que se pierden; pero a los que se salvan, esto es, a nosotros, es poder de Dios, pues está escrito: «Destruiré la sabiduría de los sabios y frustraré la inteligencia de los inteligentes.» ¿Dónde está el sabio? ¿Dónde está el escriba? ¿Dónde está el que discute asuntos de este mundo? ¿Acaso no ha enloquecido Dios la sabiduría del mundo? (I Cr 1. 18-20)

La teología de la cruz reivindica una concepción de Dios, en la cual este no puede ser accedido por la razón ni por las obras humanas. Dios no puede ser conocido por la diferencia cualitativa que separa al ser creador infinito-eterno-absoluto del ser creado finito-temporal-contingente. El pecado separa al ser humano de Dios, y lo hace inaccesible por sus propios medios humano, entre ellos por la 
razón. Para el luteranismo, todo lo que provenga de la humanidad es corruptible. La persona solo es salva por la gracia divina que emana del sacrificio de Cristo en la cruz, en donde, el ser humano es santificado por la justicia y méritos de Cristo. De esta manera, Martín Lutero opone la teología de la cruz a la teología de la gloria, la cual proviene del intento de la tradición medieval por racionalizar a Dios y acceder a lo invisible -la fe- por medio de lo visible -la razón-. Por ejemplo, los innumerables intentos del pensamiento religioso medieval por encontrar argumentos que probaran la existencia de Dios, que tenían una única finalidad esencial: dar razones para creer. La teología de la cruz niega las razones para creer, si se necesitan razones para creer no se cree, no hay fe, en definitiva. La teología de la gloria solo quiere ver a Dios en su majestad, como ser supremo, causa in-causada, ser eterno, etc. Pero se olvida de la ignominia y la humildad de la cruz, en donde Dios se hace hombre, vive y muere como cualquier mortal. No obstante, desarrolla una tarea que solo puede ser ejecutada por Dios mismo, salvar al hombre de su condenación. Recordemos el siguiente pasaje bíblico cuando Cristo estaba colgado en la cruz con dos ladrones:

Uno de los malhechores que estaban colgados lo insultaba diciendo: —Si tú eres el Cristo, sálvate a ti mismo y a nosotros. Respondiendo el otro, lo reprendió, diciendo: ¿Ni siquiera estando en la misma condenación temes tú a Dios? Nosotros, a la verdad, justamente padecemos, porque recibimos lo que merecieron nuestros hechos; pero éste ningún mal hizo. Y dijo a Jesús:-Acuérdate de mí cuando vengas en tu Reino. Entonces Jesús le dijo: - De cierto te digo que hoy estarás conmigo en el paraíso. (Lc 23. 39-43)

Uno de los ladrones increpa a Cristo, este le exige que demuestre ser Dios, que se haga evidente, que deshaga lo escandaloso -en términos de Kierkegaard- que es básicamente la paradoja, a saber: Dios humillado en la cruz como un hombre particular cualquiera. No obstante, el otro ladrón cree en Cristo como contrasentido, como lo absurdo: en la concepción luterana de la figura de Cristo, en esto consiste la esencia de la paradoja y locura de la cruz.

Finalmente, Kierkegaard concluye lo siguiente: si la comunicación directa no es posible con la divinidad, por la paradoja que está enraizada en la figura de Cristo, de aquí se sigue que, Dios como absoluto no puede ser conocido, es decir, es incognoscible. En palabras de Kierkegaard (2009, 139-40):

¿Qué es incognoscibilidad? Incognoscibilidad es no ser en sus caracteres lo que se es esencialmente, por ejemplo, cuando un policía esta vestido de civil. Y así 
es incognoscibilidad la absoluta incognoscibilidad: que cuando se es Dios, se sea un hombre individual. Ser tal hombre individual o un hombre individual (en cierto sentido es indiferente que se trate de un encumbrado o un insignificante) es la distancia máxima, la infinita distancia cualitativa de ser Dios, y por lo tanto el más profundo incognito. Más esta modernidad ha eliminado a Cristo, o desplazándolo lejos y tomando su doctrina, o convirtiéndolo en fantástico, atribuyéndole fantásticamente la comunicación directa. Otra cosa distinta acontece en la situación de contemporaneidad: y además no olvides que la voluntad de Cristo era la de mantener el incognito, cabalmente porque él quería ser signo de contradicción (...) La mayoría de los hombres que ahora viven en la cristiandad tienen la impresión de que si hubiesen vivido contemporáneamente con Cristo lo hubiesen conocido automáticamente a pesar de la incognoscibilidad (...) En el fondo se fantasea acerca de Cristo. Se le convierte en un hombre, que estaba convencido de ser algo extraordinario (...) Mas se sigue fantaseando, se imagina que Cristo en el fondo había deseado ser conocido directamente como lo extraordinario que era.

El pensador danés propone un pequeño ejemplo, para dilucidar la idea de Cristo como ser incognoscible, como un enigma. Para ello, plantea la siguiente situación: dos enamorados expresan su amor de forma evidente y clara, y acto seguido, el amado le pregunta: ¿crees tú que yo te amo? Y la amada responde que efectivamente sí lo cree. No obstante, Kierkegaard lleva más lejos la situación y formula un escenario en donde el comportamiento del amado fuese tan ambiguo que pudiera tomársele por un engañador o por el amante más fiel. Aquí aparece la duplicidad, el amado ya no puede tener una comunicación directa con su amada, ya que puede ser un engañador o un amante fiel. Es decir, el amado es un enigma. En la segunda situación, -nos dice Kierkegaard- la amada debe tomar una elección frente a la misma pregunta: ¿crees tú que yo te amo? Si ella decide por una respuesta afirmativa, entonces, ha arriesgado creerle, a pesar de carecer del conocimiento-evidencias, pruebas-sobre las intenciones de su amado. Kierkegaard, con este ejemplo, plantea que el verdadero cristianismo se asemeja mucho a la relación entre el amado y la amada, en la segunda situación planteada. En esta, la amada elige creer en el amor de su amado sin tener una demostración de ello, cree en su amor a pesar de la ambigüedad, podría ser un engañador o un amante fiel. De modo análogo, Cristo exige ser objeto de fe sin exhibirse o demostrarse con total claridad como Dios, por ende, Kierkegaard manifiesta que la fe solo tiene sentido cuando la comunicación es indirecta y al ser indirecta aparece el enigma, la incognoscibilidad. 


\section{4. ¿Tiene sentido intentar demostrar la existencia de Dios?}

En términos Kierkegaardianos, la respuesta ha de ser rotundamente negativa. El filósofo danés analiza uno de los argumentos sobre la existencia de Dios más representativos de la tradición filosófica, a saber: el denominado argumento ontológico sobre la existencia de Dios, que tiene su origen en la filosofía medieval ${ }^{1}$. En la tradición moderna

1 El argumento ontológico sobre la existencia de Dios se remonta a San Anselmo, que formula una prueba o razonamiento para demostrar la existencia de Dios. Básicamente el argumento ontológico de San Anselmo parte del siguiente presupuesto: si conocemos la esencia de Dios, entonces podemos comprobar su existencia. San Anselmo define a Dios como el ser mayor que pueda ser pensado, este planteamiento en el plano de las ideas, ha sido beneficioso para contrarrestar la opción contraria que niega la existencia de Dios. Incluso, para quienes no creen que Dios existe en el plano fáctico, pueden en sus mentes comprender la definición de Dios como el ser mayor que pueda ser pensado. La formulación de Dios como el ser mayor que pueda ser pensado no admite algo superior diferente de lo que ya es el ser mayor o superior que puede ser pensado. Por ende, si ese ser mayor o superior que puede ser pensado -Dios- solo existe en el plano de las ideas, entonces, es posible considerar un algo más perfecto a ese ser mayor o superior -Dios-, pero como no es posible hacerlo, por la definición misma de Dios como el ser mayor o superior que pueda ser pensado, entonces se concluye su existencia fáctica, porque considerar que el ser mayor o superior que pueda ser pensado no exista fácticamente contradice su definición. Desde los tiempos medievales, este argumento ha recibido críticas, por ejemplo, una de las más certeras o conocidas es la del monje Gaunilo, quien dice que, el argumento anselmiano está invertido, su conclusión es su premisa. Es decir, si aceptamos que existe efectivamente un ser mayor o superior -Dios-, entonces podemos reconocer -por ejemplo- Spinoza retoma aportes del argumento ontológico, para demostrar que solo puede existir una sustancia -Dios-. El pensamiento spinozista considera que las entidades existentes en el mundo dependen de una única sustancia-Dios-, que es entendida por el filósofo neerlandés del siguiente modo: "Por Dios entiendo el ser absolutamente infinito, es decir, la sustancia, que consta de infinitos atributos, cada uno de los cuales expresa una esencia eterna e infinita" (Spinoza 2005, 39).

Spinoza construye una comprensión de Dios anclada en varios elementos: primero, por sustancia entiende aquello que "... es en sí y se concibe por sí...”(Spinoza 2005, 43), es decir, Dios no tiene como causa de su existencia otra cosa distinta de él mismo; segundo, cuando Spinoza afirma que Dios tiene infinitos atributos se refiere a que este ser solo puede ser definido por él mismo, en su propia infinitud. Dios no solo tiene una causa de sí, ya que esta se entiende como "... Una sustancia que no puede ser producida por otra cosa..." (Spinoza 2005, 42). Toda

\footnotetext{
su existencia como una necesidad, pero su punto de partida es la existencia de Dios, aceptarla previamente. De lo contrario, siguiendo la lógica del argumento anselmiano, si consideramos que un caballo alado es el ser mayor o superior que pueda pensarse, entonces ese caballo alado debe existir fácticamente. San Anselmo refuta la posición del monje Gaunilo precisando que Dios es el único ser en el que cabe la definición como el ser mayor o superior que pueda pensarse, ya que Dios es perfecto en grado absoluto y total.
} 
causa tiene un efecto, porque "todo lo que es, o es en sí o es en otro" (Spinoza 2005, 40); en el caso de Dios, la causa es idéntica al efecto mismo, porque es en sí mismo y no en otro, es decir, Dios es a causa de sí mismo y, por ende, Dios es infinito. La sustancia no puede producir otras sustancias, Dios como única sustancia se produce a sí mismo, en la sustancia se producen modos ${ }^{2}$, que dependen en su existencia de la sustancia -Dios-. "De aquí se sigue que Dios es causa eficiente de todas las cosas que pueden caer bajo el entendimiento infinito" (Spinoza 2005, 52). En tanto que "... Dios es anterior en causalidad a todas las cosas..."(Spinoza 2005, 54), es el sustento de los modos en los que Dios se manifiesta por él y en él, por ello Dios es la causa inmanente de sus manifestaciones. La causalidad lógica y ontológica de Dios es garantizada por la concepción de Dios como única sustancia, que se concibe a sí misma sin que pueda producir otra cosa -sustancia- distinta de ella misma: "Una sustancia no puede ser producida por otra cosa, (...) será pues causa de sí, es decir, su esencia implica necesariamente su existencia, es decir, a su naturaleza pertenece el existir" (Spinoza 2005, 42).

Por otro lado, el pensador danés realiza una crítica al argumento ontológico en su versión spinozista ${ }^{3}$. Según

2 Formas en las que se manifiesta la sustancia Dios.

3 Más adelante esbozaré porque la crítica de Kierkegaard a Spinoza puede tener dificultades,
Kierkegaard, Spinoza parte del siguiente presupuesto: aquello que tiene más perfección debe tener igualmente más realidad, aquello que tiene más realidad tiene más perfección. Si tomamos a Dios como el ser más perfecto jamás pensado, su perfección implica necesariamente su existencia. Igualmente, si consideramos a Dios como el ser más real, puesto que tiene la causa de su existencia en sí mismo, por ende, no depende de otro ente para ser o existir, ello implica su grado absoluto de perfección. Kierkegaard apuntala su crítica a Spinoza marcando la confusión entre el ser de hecho y ser ideal. Cuando se plantea que un ser cuanto más perfecto es más real y, en consecuencia, cuanto más real más perfecto, se está usando una tautología que se queda en el ámbito de la idealidad o de los conceptos. Igualmente, afirmar que un ente tiene más o menos existencia o es más o menos real, es una falacia lógica que no tiene sentido proyectar en el ser de hecho. Kierkegaard nos dice que una mosca tiene el mismo ser que Dios, es decir, una mosca tiene la misma realidad de Dios, la mosca no existe menos que Dios y Dios no existe más que una mosca. En el contexto del ser de hecho, Kierkegaard propone una disyuntiva: ser o no ser, existir o

principalmente, por la forma cómo Kierkegaard plantea el argumento spinozista sobre la existencia de Dios. 
no existir, no se puede existir en grados, se existe o no se existe ${ }^{4}$.

4 La crítica de Kierkegaard a Spinoza puede tener algunas dificultades. La noción de Dios de Spinoza está referida a un panteísmo, en este panteísmo Dios y la Naturaleza son una unidad. Es decir, todo lo que existe está contenido en la única sustancia -Dios-, los seres del mundo son una manifestación de la sustancia única -Dios-, por eso Dios en la pensamiento spinozista es una causa inmanente de los otros seres -que no son sustancias sino solo manifestaciones del ser único de Dios-, que no son otro cosa que determinaciones del mismo Dios. Por ende, la perfección de Dios se desplaza de manera inmanente en sus manifestaciones, ya que, Dios y el mundo son la misma unidad, es una contradicción considerar que las manifestaciones de la sustancia son menos perfectas que la sustancia misma, las manifestaciones de Dios son inmanentes a él mismo, son una extensión de sí, por ende, no puede ser menos perfectas que la sustancia que las determina. En este sentido, la crítica de Kierkegaard a Spinoza parece recorrer un camino en arena movediza. La crítica de Kierkegaard a Spinoza parece encajar más con la posición cartesiana frente al argumento ontológico sobre la existencia de Dios. Para René Descartes, en la idea de Dios cabe un ser perfecto en infinito, entonces, ¿cómo puede una conciencia finita tener la idea de un ser perfecto e infinito? La respuesta de Descartes señala que lo imperfecto o finito no puede ser causa de lo perfecto e infinito. Entonces, se deduce que la única vía posible es que la idea de un ser perfecto e infinito provenga de un ser perfecto e infinito, es decir, de Dios mismo, por ende, Dios existe. Por lo demás, si aceptamos que Dios es un ser perfecto, entonces en su misma perfección está la condición que exige la existencia de ese ser, de lo contrario, la idea de Dios tendría su causa en la finitud de la mente humana y, por ende, Dios no existiría, dando paso a una contradicción causal expresada del siguiente modo: lo finito e imperfecto es origen de lo infinito y perfecto. Efectivamente, tal como lo propone Kierkegaard, plantear que de la perfección de Dios se sigue necesariamente su existencia es una tautología, en donde lo perfecto es lo real y lo real es lo perfecto. De ahí que, para Descartes, la idea de Dios tiene necesariamente que contener su existencia,
De otro lado, Kierkegaard nos introduce en un juego lógico sobre lo que implica la intención de demostrar la existencia de algo, que en este caso está referida a la existencia de Dios. La intencionalidad de demostrar la existencia de Dios supone previamente haber dado por sentado su existencia, de no ser así, qué sentido tendría demostrar la existencia de algo que presuponemos es inexistente. Entonces, resulta que para demostrar algo debemos suponer su existencia porque de otro modo no tendría sentido la demostración. ¿Cuál es, finalmente, el sentido de la demostración, si ya hemos dado por sentado la existencia de ese algo,

porque lo no existente no puede ser más perfecto que lo que existe. Para Kierkegaard, lo engañoso de la posición que equipara la existencia real con la perfección, es que lo real no admite grados, se existe o no se existe, no se puede existir en grados, como más o menos realidad, dependiendo de la cualidad de la perfección. Incluso, cuando Kierkegaard asevera que una mosca no tiene más ni menos existencia que Dios, lo que hace irónicamente es validar la posición spinozista, en donde la mosca es una manifestación de Dios producida por él y en él mismo, ya que Dios es la única sustancia existente, la mosca en ese sentido, participa de la misma realidad y perfección de Dios, porque Dios como sustancia única no puede engendrar nada distinto de él mismo. De otro lado, hay una diferencia sustancial entre el Dios de Spinoza y el de Kierkegaard, el del filósofo neerlandés es un panteísmo y el del filósofo danés es un teísmo. Esto presupone una diferencia esencial de lo que entienden por Dios -cada uno de ellos-, cuya oposición se manifiesta claramente en que mientras Spinoza concibe a un Dios des-antropomorfizado; Kierkegaard cree en un ser divino personal y trascendente al mundo. 


\section{para precisamente intentar demostrar-} lo $?^{5}$ Este enfoque de Kierkegaard para

5 Efectivamente, en términos lógicos la carga de la prueba debe caer sobre quien afirma la existencia de Dios, de otro lado, si se niega la existencia de Dios, entonces ¿cómo se puede probar la existencia de un algo que no existe? Es decir, no se puede demostrar la existencia de un ser inexistente -si postulamos que Dios no existe-, de forma contraria, si consideramos que existe, entonces qqué sentido tiene demostrar lo que hemos aceptado como base de la demostración -existencia de Dios-? Afinando el análisis podría decirse que, aquello que se ha aceptado en el intento de demostrar la existencia de Dios no es su existencia fáctica, sino una comprensión o entendimiento de la idea de Dios que posibilita derivar lo ontológico de lo lógico conceptual. Por ejemplo, Leibniz propone varios argumentos sobre la existencia de Dios, uno de ellos apela a la posibilidad de Dios, basado en que todo aquello que no sea lógicamente contradictorio es posible, si tenemos la idea de Dios como un ser perfecto, y si una manifestación de la perfección de Dios es la existencia, entonces Dios existe porque no hay contradicción alguna entre la perfección de Dios y su existencia, por ende, es posible, y en tanto es posible, existe. También, Leibniz propone que si consideramos a Dios como ser necesario, esta idea no es contradictoria con la existencia, por ende, es posible y, si es posible, existe, dado que si ese ser necesario -Dios- no existiera, entonces, nada podría existir, pero si existe algo, el ser necesario existe, porque si ese ser necesario no existiera, entonces, nada podría existir. Igualmente, Leibniz formula que los entes existentes gozan de una armonía preestablecida, es decir, el orden cósmico solo puede ser garantizado por un ser superior, y por ende, el conocimiento racional de esa armonía preestablecida -orden cósmicopermite conocer a Dios, en una forma indirecta, es decir, a través de una armonía que mueve al cosmos, que tiene finalmente su fundamento en la divinidad. El acceso racional a Dios quiere defender la idea de que hay razones para creer, y este ideal ha sido perseverante -refiriéndonos al cristianismo- en la tradición medieval y moderna -en algunos filósofos-, no obstante, el punto de partida para dar razones para creer es la fe, no se trata de dar razones para creer -elegir creer-, intentar ahogar las razones para creer es musugestivo, porque el mensaje es mucho más radical: aun cuando existan razones para creer $-\mathrm{y}$ estas tengan soporte lógico o argumentativo-, esto no es fe, de esta forma no nos podemos acercar a la divinidad, por lo menos no desde un aproximación genuina y sincera. Finalmente, desde la perspectiva racional, toda pretendida argumentación sobre la existencia de Dios

sino de dar razones para confirmar la fe -fundamentar lo que ya se ha elegido-, para confirmar con elementos racionales -en la medida de lo posible- lo que se ha aceptado por fe, que es precisamente el circulo vicioso -o tautología- en el que se ha quedado el argumento ontológico sobre la existencia de Dios en sus múltiples variantes. En otras palabras, para llegar a aceptar la existencia de Dios en términos ontológicos, se parte de unos presupuestos teóricos o ideales que la derivan implícitamente. El sentido del acceso racional a Dios es contradecir la suposición del absurdo de la fe, la irracionalidad, el sin sentido de Dios. En la tradición filosófica medieval el logos griego se une al logos divino, el pensamiento o razón divina se proyecta en la razón humana, de este modo, fe y razón no rivalizan sino que se complementan, ya que la razón humana hace parte del acto creador del logos divino. No obstante, para algunos filósofos el acercamiento racional a Dios no permite demostrar su existencia con absoluta certeza. En ese sentido -por ejemplo- Blaise Pascal apunta a lo siguiente: el vacío de Dios es una apuesta existencial, que el ser humano no ha podido resolver por medios racionales, afirmar o negar la existencia de Dios. Por ende, se cae en un vacío que está reflejado en la disyuntiva, creer o no creer. Pascal lo resolvió de una manera muy particular, a través de una apuesta que en definitiva es una elección. Básicamente, la apuesta en su formulación elemental pascaliana queda expresada del siguiente modo: si no creemos y Dios existe perdemos, si creemos y Dios no existe no perdemos, al igual que si creemos y Dios existe ganamos; el incrédulo solo gana si efectivamente Dios no existe. 
puede ser objetada por medio de la misma lógica racional, mostrando sus contradicciones y falacias lógicas. Pero creer en la existencia de Dios desde la fe personal, apasionada, sin necesitar razones o argumentos que la validen, consolida la creencia religiosa en un acto puro, de entrega total a un Dios que no puede ser comprendido racionalmente, únicamente puede ser creído y vivido en un acto de $\mathrm{fe}^{6}$.

6 La crítica de Kierkegaard a la metafísica radica que esta presupone un análisis objetivo de la realidad, de su fundamento último -en este caso Dios- y de cómo este fundamento último sustenta o fundamental la realidad en su conjunto. Para Kierkegaard, el acercamiento metafísico presupone la reflexión, y en esa medida puede tener una pretensión de verdad objetiva. Para el pensador danés, la verdad realmente importante es la subjetiva, porque implica la conciencia. Es decir, la relación que plantea el individuo en términos de su conciencia -subjetividad-con lo que considera vital para él, en este caso, Dios es lo realmente verdadero. Dios es una verdad subjetiva porque es una verdad para mi conciencia y solo tiene sentido como verdad subjetiva, como verdad de conciencia. Por el contrario, la verdad como reflexión significa plantear un distanciamiento con el objeto de la reflexión, para Kierkegaard, se realiza un proceso de exteriorización, que presupone un acercamiento desinteresado con esa realidad. Es decir, la dimensión discursiva racional de la metafísica propone a Dios como representación, no como conciencia, porque lo importante no es develar la estructura metafísica del mundo -objetividad-, sino establecer una relación con Dios en términos de conciencia y de interés personal. Kierkegaard deslegitima la reflexión metafísica sobre Dios. No obstante, es pertinente considerar el sentido o significado que tiene la divinidad para el individuo concreto -en su conciencia personal-, sumado a esto, también se hace necesario referenciar el lugar que ocupa ese ser como fundamento de la realidad en su máxima expresión. De esta forma, cabe incluso preguntar cómo afecta nuestra forma de conocer

\section{Consideraciones finales}

La anterior exposición sobre la concepción de Dios como verdad subjetiva y paradoja nos lleva a considerar que Kierkegaard defiende una posición fideísta, que se caracteriza por "una radicalización de la fe, pues el fideísmo sostiene que las verdades metafísicas y morales son inaccesibles a la razón humana y, por tanto, deben aprehenderse sólo mediante la fe" (Lacueva 2001, 290). En este sentido, si se necesitan razones para creer, entonces no hay fe, no se trata de una fe genuina. Este punto nos conecta con la propuesta central del filósofo danés, a saber: la creencia en Dios requiere de un compromiso personal, basado en un convencimiento que no es fruto de la razón. Entonces, el convencimiento sobre Dios emerge de un acto de fe completamente ciego y confiado en lo que el luteranismo denomina como la locura de la cruz.

la realidad el ser divino. De manera irónica podemos cuestionarnos: ¿si la posición kierkegaardiana no cae en la trampa de la reflexión, ya que su postura religiosa solo puede ser expresada al interior de un saber filosófico, cosificada en el discurso y lenguaje filosófico teológico? En ese sentido, Kierkegaard nos presenta una representación de Dios, que solo puede ser accedida por reflexión, ya que la conciencia y la vivencia interior -entre Kierkegaard y Dios- no la podemos asimilar o conocer - que por esencia es una experiencia subjetiva-, únicamente podemos hacernos una representación de ella a través de una elaboración filosófico-teológica -realizada por el propio Kierkegaard- que es exterior a esa experiencia interior -verdad subjetiva de Dios-. 
A partir de lo anterior, se desprende un llamado de atención -no aleccionador o moralista- a vivir una fe transparente, realmente comprometida. Kierkegaard nunca pretendió presentarse como un verdadero cristiano, por el contrario, sostenía que tenía dudas sobre la naturaleza de sus convicciones, es decir, si realmente estaba comprometido con la fe, o tan solo se trataba de una vida religiosa superficial, artificial y, por ende, alejada realmente de Dios. Incluso, consideró que era muy fácil para los cristianos estar del lado de la cristiandad -incluyéndose él mismo- .

Lo interesante de la visión religiosa de Kierkegaard sobre Dios es que hace una fractura con la razón, produciendo un abismo entre fe y razón. Generalmente, cuando se intenta hacer un puente o crear canales de comunicación entre la fe y la razón, aquellos que están del lado de la fe intentan formular razones para creer, apelando a argumentos filosóficos, históricos, sociológicos, antropológicos, arqueológicos, hasta biológicos -como el argumento del diseño inteligente-. Esto queda expuesto -por ejemplo- en los debates públicos que grandes intelectuales ateos y creyentes del siglo XXI realizan alrededor de la fe cristiana, como es el caso del debate entre el biólogo ateo inglés Richard Dawkins y el arzobispo de Canterbury, Rowan Williams, de la iglesia anglicana, realizado en el año
2012, que atrajo títulos de la prensa mundial como el siguiente: "Batalla dialéctica en Oxford entre la ciencia y la fe" (Fresneda 2012). En términos kierkegaardianos -por lo menos desde la fe cristiana-, quien decida creer no necesita razones para creer, la fe es un movimiento de abandono de la razón. La sentencia de Kierkegaard frente a la disyuntiva entre fe y razón es fulminante: se cree o no se cree.

\section{Bibliografía}

Balderas Vega, Gonzalo. 2013. Kierkegaard y la experiencia paradójica de la fe en el Dios de Jesucristo. México: Universidad Iberoamericana.

Fazio, Mariano. 2007. Søren Kierkegaard. En Philosophica: Enciclopedia filosófica online. Recuperado de < http://www.philosophica.info/voces/kierkegaard/ Kierkegaard.html>

Fresneda, Carlos. 2012. Batalla dialéctica en Oxford entre la ciencia y la fe. Periódico El Mundo. Recuperado de <http://www.elmundo.es/elmundo/2012/02/23/ ciencia/1330027135.html>

González, Justo L. 2010. Diccionario manual teológico. Barcelona: Editorial CLIE.

Kierkegaard, Søren. 1999. Migajas filosóficas (Trad. Rafael Larrañeta). Madrid: Editorial Trotta. 
Kierkegaard Søren. 2009. Ejercitación del cristianismo (Trad. Demetrio Gutiérrez Rivero). Madrid: Editorial Trotta.

Lacueva, Francisco. 2001. Diccionario teológico ilustrado. Barcelona: Editorial CLIE.

Lutero, Martín. 1518. La disputación de Heidelberg. Recuperado de $<$ https://sites.google.com/site/ iglesialuteranariocuarto/biblioteca-martin-lutero/biblioteca-martin-lutero_1517-a-1520>

Lutero, Martín. 1519. Cómo meditar en la pasión de Cristo. Recuperado de <https://sites.google.com/ site/iglesialuteranariocuarto/biblioteca-martin-lutero/biblioteca-martin-lutero_1517-a-1520>
Ropero, Alfonso. 1999. Una introducción a la filosofía: Una perspectiva cristiana. Barcelona: Editorial CLIE.

Russ, Jacqueline. 1999. Léxico de filosofía: los conceptos y los filósofos en sus citas. Edición española de Fernando Guerrero Jiménez. Madrid: Ediciones Akal, 1999. Impreso.

Santa Biblia. Versión Reina Valera, 1960.

Spinoza, Baruch. 2005. Ética demostrada según el orden geométrico. Madrid: Editorial Trotta.

Strathern, Paul. 1999. Kierkegaard en 90 minutos. Madrid: Siglo XXI Editores. 
